\title{
Effects of experimental conditions and of addition of natural minerals on syngas production from lignin by oxy-gasification: Comparison of bench- and pilot scale gasification
}

\author{
Filomena Pinto ${ }^{\mathrm{a}, *}$, Rui Neto André ${ }^{\mathrm{a}}$, Carlos Carolino ${ }^{\mathrm{a}}$, Miguel Miranda ${ }^{\mathrm{a}}$, Pedro Abelha ${ }^{\mathrm{a}}$, Daniel Direito ${ }^{\mathrm{a}}$, \\ Jesper Dohrup $^{b}$, Hanne Risbjerg Sørensen ${ }^{b}$, Francisco Girio ${ }^{a}$ \\ ${ }^{\text {a }}$ LNEG, Estrada do Paço do Lumiar, 22, 1649-038 Lisboa, Portugal \\ ${ }^{\mathrm{b}}$ DONG Energy, Kraftværksvej 53, DK-7000 Frederica, Denmark
}

\section{H I G H L I G H T S}

- Oxygen blown gasification of spent lignin from a second-generation cellulosic ethanol plant.

- Oxy-gasification of a biomass fraction (lignin) with high tendency for tar formation.

- Oxy-gasification of a biomass fraction with high contents of silica and alkaline metals.

- Confirmation of bench-scale oxy-gasification results at pilot-scale.

- Hot syngas cleaning and upgrading in a two fixed bed catalytic reactors installation.

\section{A R T I C L E I N F O}

\section{Article history:}

Received 17 April 2014

Received in revised form 14 July 2014

Accepted 11 September 2014

Available online 26 September 2014

\section{Keywords:}

Gasification

Lignin

Tar abatement

Gaseous hydrocarbons abatement

\begin{abstract}
A B S T R A C T
Gasification of spent lignin pellets was used to obtain a gas suitable for energy production. Spent lignin was obtained from second-generation cellulosic ethanol demo plant using wheat straw as feedstock. Gasification of lignin did not give rise to any feeding problems, thus no significant changes were needed in the existing gasification installation. The rise of temperature and steam flow rate favoured the formation of $\mathrm{H}_{2}$, while hydrocarbons $\left(\mathrm{C}_{n} \mathrm{H}_{m}\right)$ and tar contents decreased. The increase of equivalent ratio (ER) also decreased hydrocarbons and tar contents, but syngas higher heating value (HHV) was reduced. The use of natural minerals improved lignin gasification. The presence of dolomite led to the highest $\mathrm{H}_{2}$ and to the lowest $\mathrm{C}_{n} \mathrm{H}_{m}$ and tar contents. Results obtained at bench-scale were confirmed at pilot-scale, as similar trends were obtained. However, as the residence time in pilot gasifier was higher, greater gas yields with higher $\mathrm{H}_{2}$ and $\mathrm{CH}_{4}$ concentrations were obtained, while tar contents decreased. After syngas hot cleaning and upgrading, the final syngas composition showed to be suitable for a wide range of applications (e.g. energy production and synthesis of chemicals), since it was substantially enriched in hydrogen, whereas tar and heavier gaseous hydrocarbons were completely destroyed.
\end{abstract}

(c) 2014 Elsevier Ltd. All rights reserved.

\section{Introduction}

Lignocellulosic (LC) materials are mainly composed of cellulose, hemicelluloses and lignins. During hydrothermal processing of LC biomass fractionation, followed by enzymatic hydrolysis operation units of second generation bioethanol production, cellulose is hydrolysed and hemicelluloses are depolymerized forming oligomers and monomers, releasing lignins as spent solids. Lignin is the worlds' second most abundant natural polymer containing

\footnotetext{
* Corresponding author. Tel.: +351 210924787.

E-mail address: filomena.pinto@lneg.pt (F. Pinto).
}

valuable aromatic (phenolic) structures. Lignins are constituted by phenolic compounds, whose precursors are three aromatic alcohols: p-coumaryl, coniferyl and sinapyl alcohols, which are linked together with about two-third of ether bonds $(\mathrm{C}-\mathrm{O}-\mathrm{C})$ and around one-third of $\mathrm{C}-\mathrm{C}$ bonds [1]. Lignin structure presents several functional groups: methoxyl, phenolic hydroxyl, aliphatic hydroxyl, benzyl alcohol, noncyclic benzyl ether and carbonyl groups [2]. Lignin is the main constituent of large residual streams in the pulp and paper sector and future cellulosic bioethanol plants, other biorefineries, etc. Only about $2 \%$ of lignin based materials is currently used for other applications than combustion. Lignin may be used in different applications and processing: direct application in resins, 